\title{
Verification and Validation Strategy for LWRS Tools
}

Carl Stoots, Tom Larson, Richard Schultz, Hans Gougar, Kathryn McCarthy, and David Petti (INL); Laura Swiler (Sandia); Michael Corradini (U. of Wisc)

September 2012

The INL is a U.S. Department of Energy National Laboratory operated by Battelle Energy Alliance 


\section{DISCLAIMER}

This information was prepared as an account of work sponsored by an agency of the U.S. Government. Neither the U.S. Government nor any agency thereof, nor any of their employees, makes any warranty, expressed or implied, or assumes any legal liability or responsibility for the accuracy, completeness, or usefulness, of any information, apparatus, product, or process disclosed, or represents that its use would not infringe privately owned rights. References herein to any specific commercial product, process, or service by trade name, trade mark, manufacturer, or otherwise, does not necessarily constitute or imply its endorsement, recommendation, or favoring by the U.S. Government or any agency thereof. The views and opinions of authors expressed herein do not necessarily state or reflect those of the U.S. Government or any agency thereof. 
INL/EXT-12-27066

Revision 0

\section{Verification and Validation Strategy for LWRS Tools}

Carl Stoots, Tom Larson, Richard Schultz, Hans Gougar, Kathryn McCarthy, and David Petti (INL);

Laura Swiler (Sandia); Michael Corradini (U. of Wisc)

September 2012

Idaho National Laboratory

Experimental Programs

Idaho Falls, Idaho 83415

http://www.inl.gov

Prepared for the

U.S. Department of Energy

Office of Nuclear Energy

Under DOE Idaho Operations Office

Contract DE-AC07-05ID14517 


\section{SUMMARY}

The US Department of Energy Light Water Reactor Sustainability (LWRS) Program is focused on enabling the long-term operation of US commercial power plants. Commercial power plant owners will make the decisions on life extension - the information provided by the research and development activities in the LWRS Program will reduce the uncertainty (and therefore the risk) associated with making those decisions.

Modeling and simulation activities are an important part of the LWRS Program. Advanced tools that represent more accurately (when compared with currently used tools) the behavior of nuclear power plants, in particular as they age, can be an important tool to inform life extension decisions, and could potentially be used in licensing activities. However, before these tools can be used to inform decisions or support licensing activities, they will need to be adequately verified and validated (V\&V'ed). The acceptable level of $\mathrm{V} \& \mathrm{~V}$ is ultimately the decision of the nuclear power plant owners (who would use the tools to inform life-extension decisions) and the NRC (if the tools are used to support licensing).

Although this report is focused on the LWRS Program, it is broadly applicable to advanced modeling and simulation activities.

Significant and continuing advances in computer simulation and rising costs of building and conducting test facilities are increasing the reliance on complex models in licensing facilities, optimizing designs, improving performance, and understanding the underlying science. At the same time, however, the complexity of these models and associated computational methods present unprecedented challenges for code verification, validation, and uncertainty quantification (VVUQ).

In general, the VVUQ Strategy should:

1. Be driven by the needs of the users (for this program, the LWR industry)

2. Distinguish between and address the needs of licensing, design and performance, and aging/life extension

3. Demonstrate the effectiveness of the methodology by executing one or more well-defined problems early in the process to establish good practices and instill confidence within the user community

4. Utilize a rigorous and integrated approach to code development and VVUQ that is accepted by industry (to inform life-extension decisions) and regulators (if the tools are used to support licensing)

5. Recognize the complementary nature of system and multiphysics/multiscale codes, addressing the unique challenges in VVUQ including gaps in understanding (physical models) and coupling of phenomena across physics, time and length scales

6. Acknowledge and identify gaps in data and re-establish the pedigree of legacy data, exploiting it in a cost-effective manner. 


\section{CONTENTS}

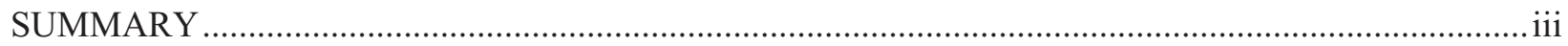

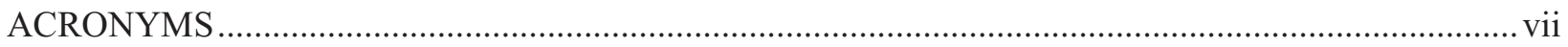

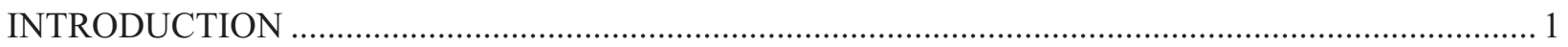

AN HISTORICAL PERSPECTIVE OF NUCLEAR PLANT VERIFICATION AND

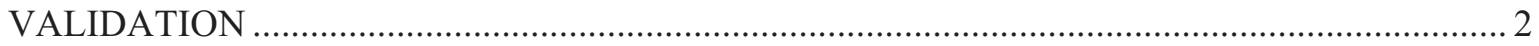

THE STRATEGY FOR VERIFICATION, VALIDATION, AND UNCERTAINTY

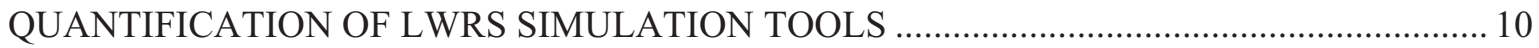

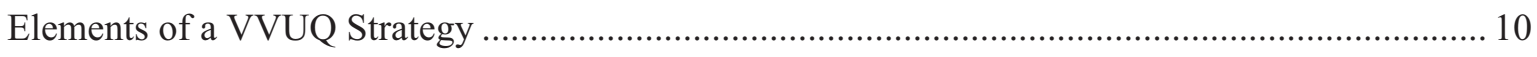

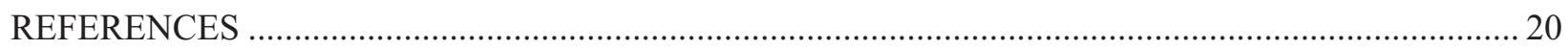

FIGURES

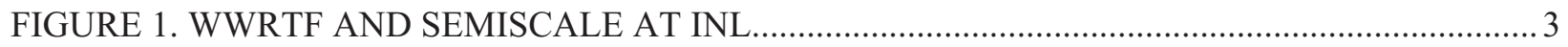

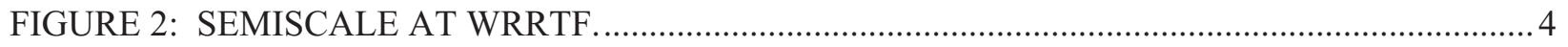

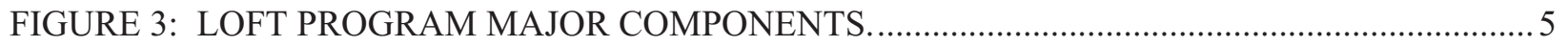

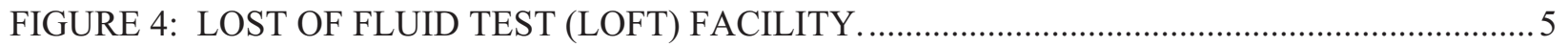

FIGURE 5: APEX FACILITY AT OREGON STATE UNIVERSITY ….......................................... 6

FIGURE 6: TOPFLOW THERMAL HYDRAULIC FACILITY IN GERMANY ................................. 6

FIGURE 7: INL MIR TEST SECTION WITH PIV SYSTEM IN PLACE. .......................................... 7

FIGURE 8: EXAMPLE CROSS CORRELATION MATRIX FROM THE NGNP PROGRAM.............. 8



FIGURE 10: HIERARCHY OF EXPERIMENTS IN A VALIDATION MATRIX............................... 15

FIGURE 11: ELEMENTS OF EVALUATION MODEL DEVELOPMENT AND ASSESSMENT PROCESS (EMIDAP). THIS COMPRISES AN INTEGRATED STRUCTURE FOR TECHNICAL ISSUE RESOLUTION (ISTIR). 17

FIGURE 12: RELATIONSHIP OF VALIDATION DATA TO CALCULATION AND SYSTEM ENVELOPES. 18 


\section{ACRONYMS}

AHP

analytical hierarchical process

BWR

boiling water reactor

CASL Consortium for Advanced Simulation of Light Water Reactors

CFD computational fluid dynamics

DOD Department of Defense

ECCS emergency core cooling system

EM evaluation model

EMDAP evaluation model development and assessment process

ERCOFTAC European Research Community on Flow, Turbulence and Combustion

IET integral effects test

ISTIR integrated structure for technical issue resolution

LOCA loss-of-coolant accident

MIR Matched Index of Refraction

NEAMS Nuclear Energy Advanced Modeling and Simulation

NGNP Next Generation Nuclear Program

NPARC National Project for Applied-Oriented Research

NRC Nuclear Regulatory Commission

PIRT phenomena identification and ranking table

PTS pressurizes thermal shock

RISMC risk informed safety margin characterization

SET separate effects test

SRP standard review plan

TOPFLOW Transient TwO Phase FLOW

TVA Tennessee Valley Authority

$\mathrm{V} \& \mathrm{~V} \quad$ verification and validation

VHTR very high temperature reactor

VVUQ code verification, validation, and uncertainty quantification

WRRTF Water Reactor Research Test Facility 


\section{INTRODUCTION}

In the United States, domestic demand for electricity is expected to grow by more than $30 \%$ from 2009 to $2035^{1}$. Despite a near halt in new construction for more than 30 years, US reliance on nuclear power has continued to grow. In 1980, nuclear plants produced approximately $11 \%$ of the US electricity. By 2010 , the 104 operating nuclear power plants in the US produced over $20 \%$ of the country's electricity. The average capacity factor has risen from $50 \%$ in the early 1970 s, to $70 \%$ in 1991 , and it passed $90 \%$ in 2002. Since 2001 these plants have maintained an average capacity factor of over $90 \%$. However, almost all of the US nuclear generating capacity comes from reactors built between 1967 and the late 1970s. Thus, the original 40-year licenses for most of the currently operating nuclear power plants were to expire before 2020. However, almost all operating nuclear power plants have been issued, are applying for, or plan to apply for a 20 -year license extension, resulting in a licensed operating period of 60 years. In about the year 2030, unless subsequent license renewals are granted, decommissioning of the current fleet of nuclear power plants will begin. Maintaining the safe and economic operation of our existing fleet of nuclear power plants for a longer-than-initially-licensed lifetime is an essential component to meeting future electrical demand. Lifetime extension of existing nuclear power plants becomes even more important when considering the administration's goals of reducing greenhouse gas emissions to $80 \%$ below 1990 levels by the year 2050 .

The vision of the Department of Energy (DOE) Light Water Reactor Sustainability (LWRS) program is:

"The existing operating fleet of nuclear power plants will continue to safely provide clean and economic electricity well beyond their first license extension period, significantly contributing to reduce U.S. and global carbon emissions and enhance national energy security and protecting the environment. There is a comprehensive technical basis for licensing and managing the long-term safe, economical operation of nuclear power plants. Sustaining the existing operating U.S. fleet will also improve its international engagement and leadership on nuclear safety and security issues."2

The LWRS program is divided into four technical pathways: 1) Materials Aging and Degradation, 2) Advanced Instrumentation, Information, and Control Systems Technologies, 3) Risk-Informed Safety Margin Characterization, and 4) Advanced Light Water Reactor Nuclear Fuels.

Modeling and simulation activities are an important part of several of the LWRS Pathways. Advanced tools that represent more accurately (when compared with currently used tools) the behavior of nuclear power plants, in particular as they age, can be an important tool to inform life extension decisions, and could potentially be used in licensing activities. However, before these tools can be used to inform decisions or support licensing activities, they will need to be adequately verified and validated (V\&V'ed). ${ }^{\text {a }}$ The acceptable level of $\mathrm{V} \& \mathrm{~V}$ is ultimately the decision of the nuclear power plant owners (who would use the tools to inform life-extension decisions) and the NRC (if the tools are used to support licensing).

a. Verification is "The process of determining that a model implementation accurately represents the developer's conceptual description of the model and the solution to the model." Validation is defined as "The process of determining the degree to which a model is an accurate representation of the real world from the perspective of the intended uses of the model." V\&V is an emerging technology for assessing the credibility of computer models. In general, validation requires comparison of code predictions with relevant experimental measurements of known accuracy. (AIAA Guide for the Verification and Validation of Computational Fluid Dynamics Simulations, AIAA Standards G-0077-1998e) 
This report provides a strategy to support the future development of a V\&V plan (currently planned for FY-13). While several of the LWRS pathways are developing models that will need some level of V\&V, the examples provided in this report focus on the Risk Informed Safety Margin Characterization (RISMC) Pathway; the strategy, however, is broadly applicable, including outside of the LWRS program. The purpose of the RISMC Pathway is to support plant decisions for risk-informed margins management with the aim to improve economics, reliability, and sustain safety of current nuclear power plants. Part of this pathway is focused on the development of advanced tools for safety assessment that enable more accurate representation of a nuclear power plant safety margin. ${ }^{2}$ The RISMC Pathway has the goal of providing tools that are mature enough to support the first decisions on second life extension license applications; these first decisions will likely be in the 2015-2020 time frame.

Advanced multiphysics models offer the potential to reduce uncertainty and increase accuracy because of the more accurate physics embodied in the models. Such tools however, pose a significantly greater challenge in $\mathrm{V} \& \mathrm{~V}$ because of the greater level of coupling and high spatial and temporal resolution. A few sample problems to demonstrate this capability are needed. Such problems can help ultimate end users decide the applicability of these advanced tools in addressing their problems. Initially they will be used by industry to inform decisions - should a subsequent license renewal be pursued? Can they or should they be used for licensing?

The US federal government has an extensive history of sponsoring nuclear plant simulation code validation efforts. Equally extensive programs have been conducted in Europe and elsewhere. These efforts generally focused on large and expensive integral experiments that yielded important yet often limited data on plant safety behavior. These data may be of considerable value to the LWRS program if the data can be adequately retrieved and re-qualified. Now however, new measurement techniques, simulation methods, and issues related to plant life extension are placing heavy demands on codes and models. Nonetheless, valuable lessons can be learned from the earlier programs.

This strategy report will be used in discussions with the LWRS industry partners to further develop V\&V plans. Current V\&V activities should be informed by the extensive history of V\&V activities both within and outside of the nuclear industry. The following section provides an historical perspective of nuclear plant validation and verification.

\section{AN HISTORICAL PERSPECTIVE OF NUCLEAR PLANT VERIFICATION AND VALIDATION}

Software V\&V probably dates back to the early 1970s Safeguard Anti-Ballistic Missile System program of the U.S. Army. It is currently in wide use by organizations such as the Department of Defense, Department of Energy, FAA, NASA, and European Space Agency ${ }^{3}$. The V\&V process has been variously standardized and codified by the Institute of Electrical and Electronics Engineers 1012-1986 and $1059-1993^{5}$, the American Nuclear Society ANS-10.4-1987 . The American Society of Mechanical Engineers is currently working on ASME Code \& Standard V\&V 30, "Verification and Validation in Computational Simulation of Nuclear System Thermal Fluids Behavior."

Specific to nuclear reactor safety, there has been approximately 40 years of both code development and experimental programs. Initially, most analyses were of transients and loss-of-coolant accidents (LOCAs) in light water reactors. In the early 1970s, the emphasis was on large break LOCAs, but by the mid-70s analyses were also addressing small break accidents and transients. Experimentally, the progression was very similar. The first integral tests concentrated on large break issues, and progressed to address transients, small breaks, and beyond design basis accidents. Experiment scaling methodologies began to attract significant attention in the 1980s to design separate effects tests (SETs) for individual phenomena. SETs offer a more highly controlled environment as well as lower cost over integral effects tests (IETs).

The ROSA (Rig-of-Safety Assessment) Program was started in 1970 at the Japan Atomic Energy Research Institute (now the Japan Atomic Energy Agency) to study thermal-hydraulic response of LWRs 
during LOCAs and operational transients ${ }^{7}$. ROSA-I was first designed for separate-effect tests mainly for fundamental blowdown phenomena and core heat transfer. The ROSA program proceeded to study the effectiveness of the emergency core cooling system (ECCS) via system integral tests for PWRs (ROSAII) and for BWRs (ROSA-III). These earlier phases of the ROSA Program utilized rather small test facilities with a half-height core and pressure vessel.

Also occurring in the 1970s, RELAP4 development and assessment needs drove design of SemiScale and LOFT experimental matrices. The Semiscale facility development began in the late 1960s and ended in the late 1980s. Semiscale, located at the Water Reactor Research Test Facility (WRRTF) (Figure 1) was a single-loop, 1-1/2 loop, and ultimately 2-loop electrically heated scaled model of a Westinghouse LPWR (Figure 2). It utilized a full-length electrically heated core simulator (maximum power $2 \mathrm{MW}$ ). The primary coolant system consisted of a pressure vessel, two circulation coolant loops (1:3 ratio) and associated Emergency Core Coolant Systems (ECCS) (accumulators, high and low-pressure injection). Elevation relationships were scaled 1:1 with the full-scale plant. The system was highly instrumented and featured an external pipe downcomer on the vessel permitting direct measurement of coolant density in the core bundle.

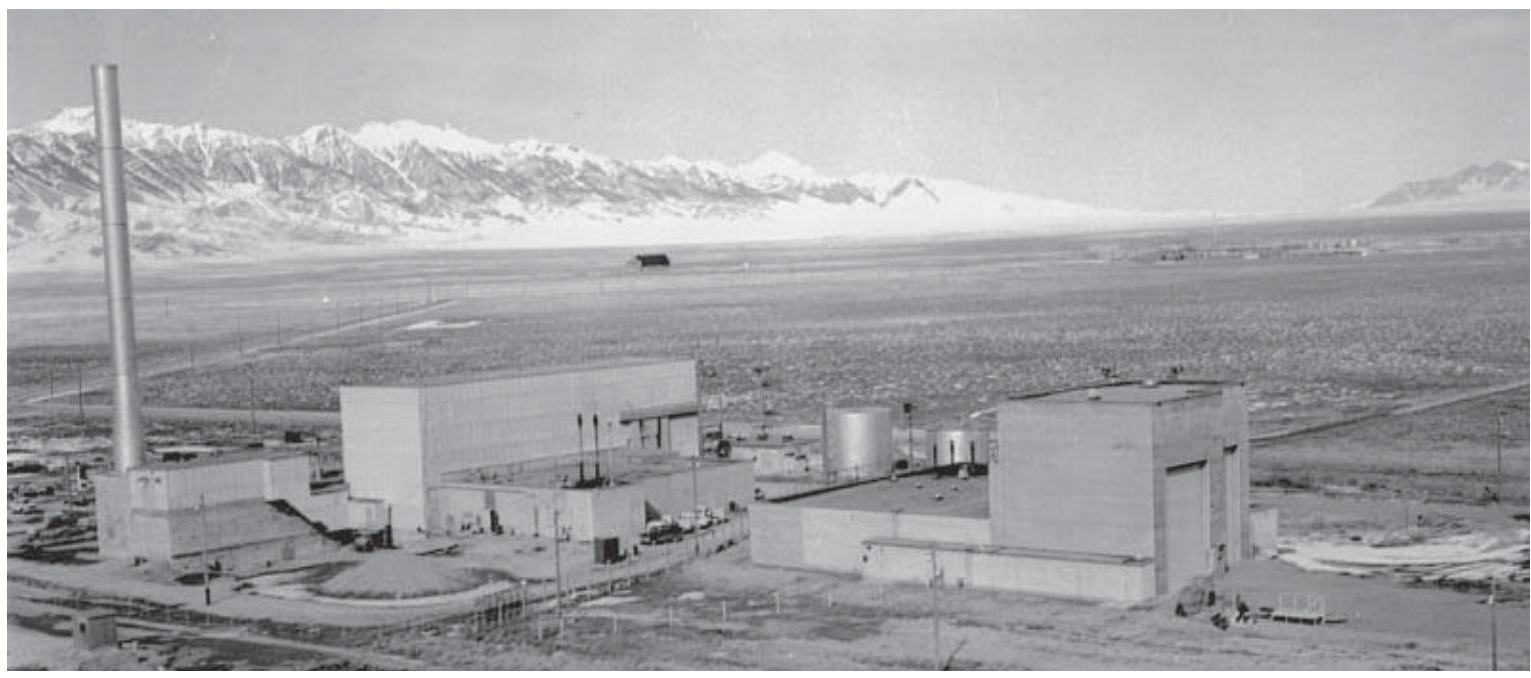

Figure 1. WWRTF and Semiscale at INL. 


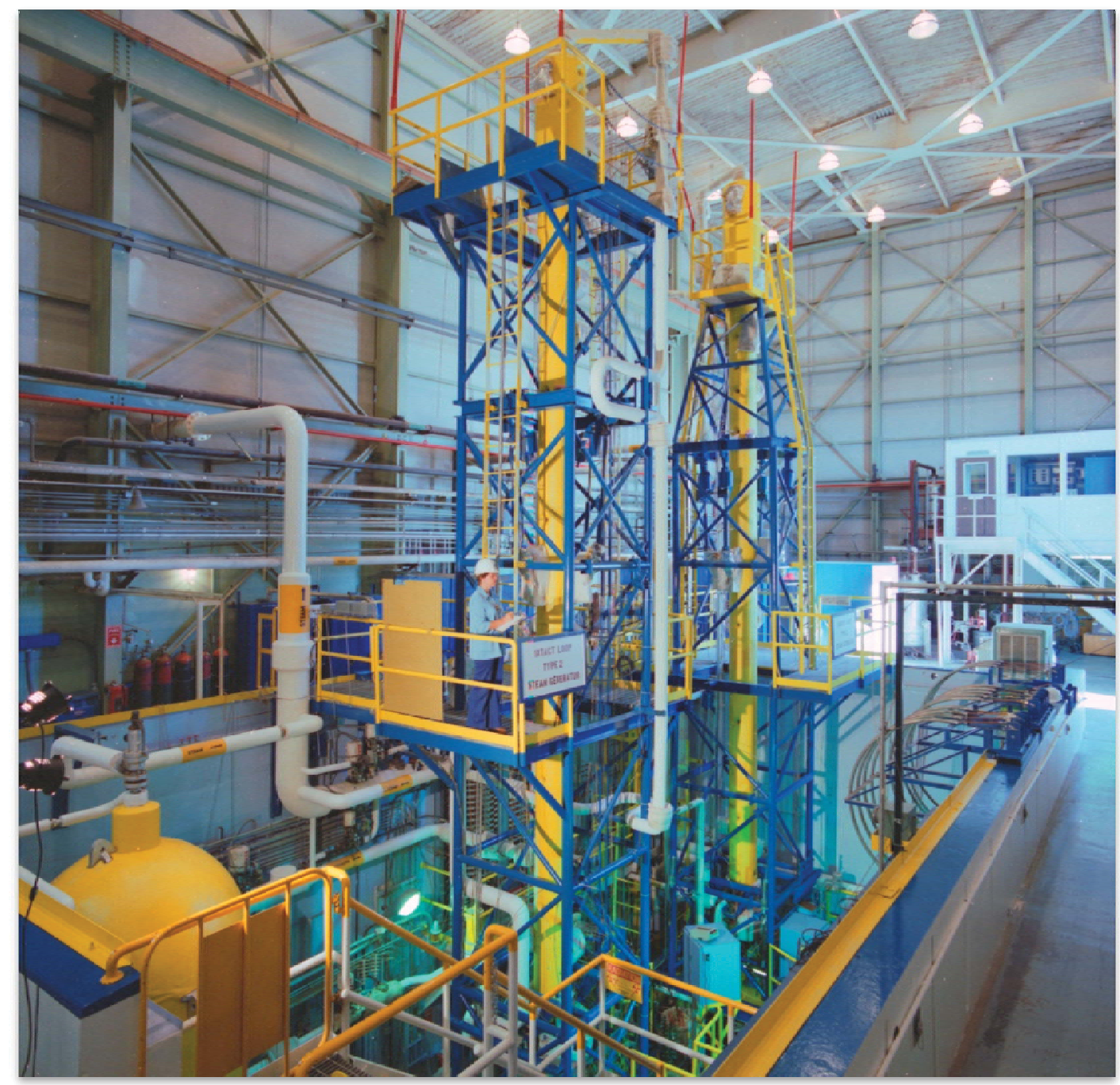

Figure 2: Semiscale at WRRTF.

The Loss of Fluid Test (LOFT) facility, a $55 \mathrm{MW}$ pressurized water reactor scaled to simulate the behavior if a $1000 \mathrm{MW}$ commercial reactor, operated from 1976 - 1985 (see Figures 3 and 4). The LOFT facility was designed to provide data from an integral nuclear system on the behavior of commercial PWRs during LOCAs and anomalous transients. The initial portion of the LOFT test program was performed without the nuclear core installed. 


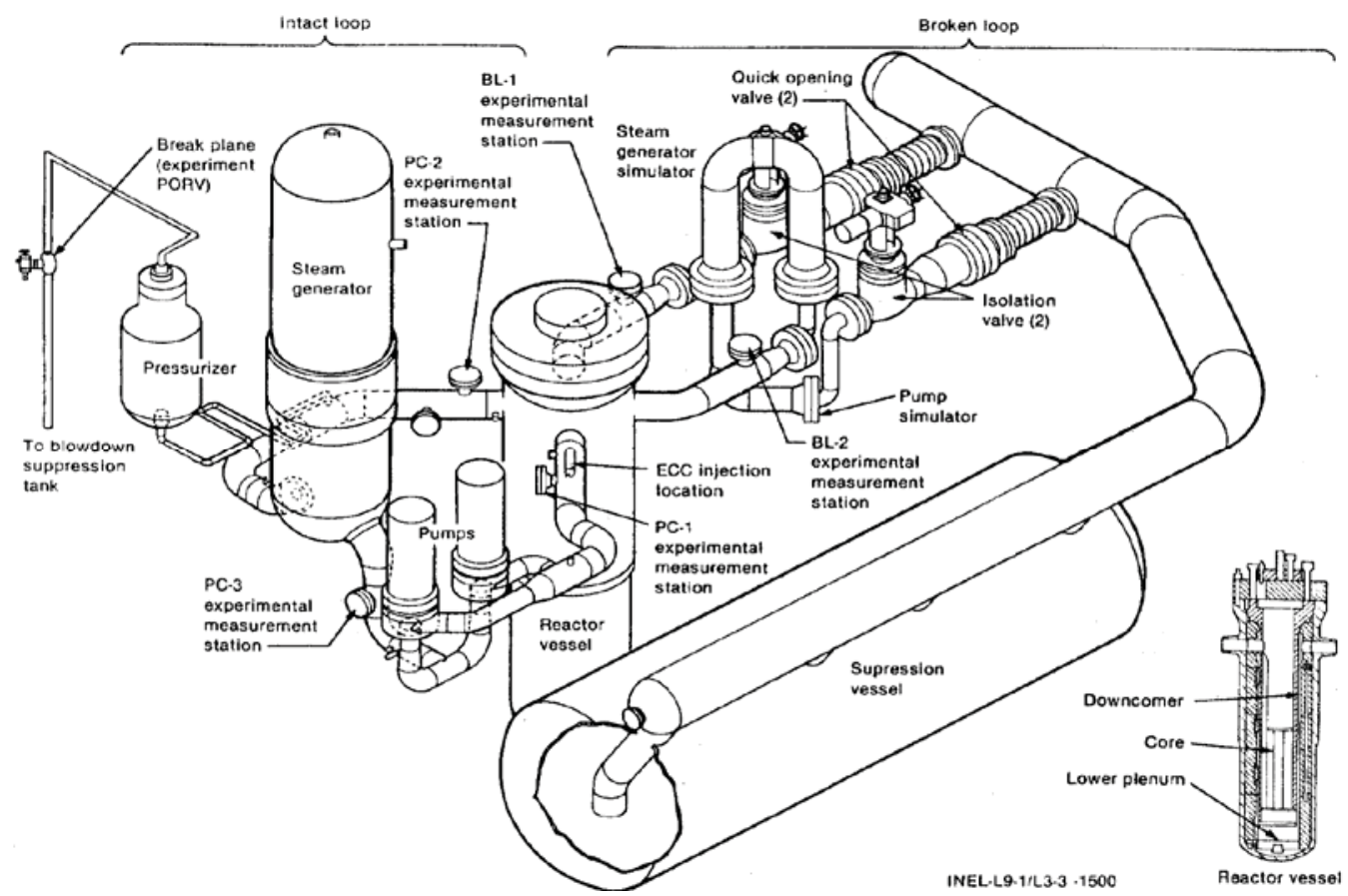

Figure 3: LOFT program major components.

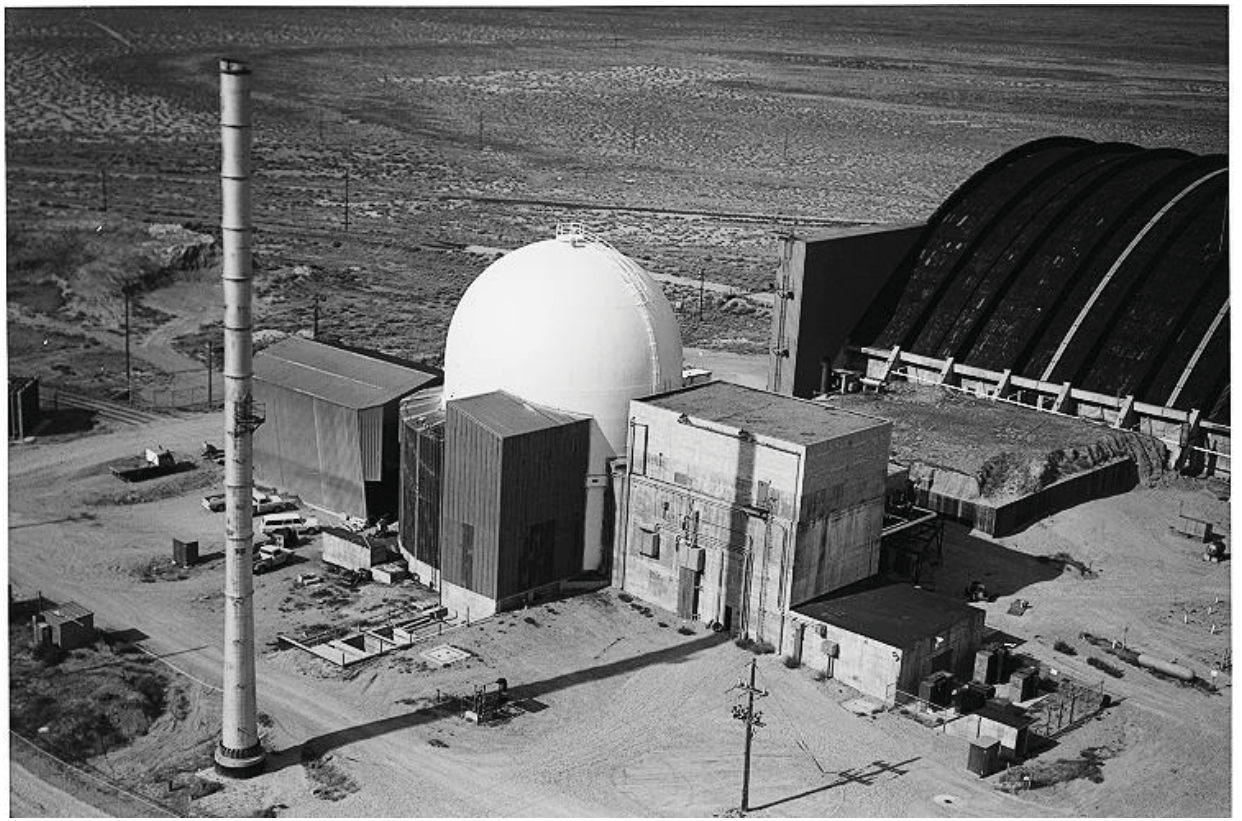

Figure 4: Lost of Fluid Test (LOFT) facility.

Experiments in the LOFT and Semiscale facilities were directed at validating the accuracy of computer models simulating loss-of-coolant accidents. In particular, what was then considered to be the worst-case scenario: a double-offset shear of a primary coolant pipe. The occurrence of the Three Mile Island reactor accident in 1979 immediately changed the direction of reactor safety programs worldwide to the investigation of small-break and mid-size break accidents with complications such as loss of off-site power. Large-scale tests continued in the US, and Japan started the ROSA-IV program in 1980, which included a large-scale integral simulation of a Westinghouse-type PWR. 


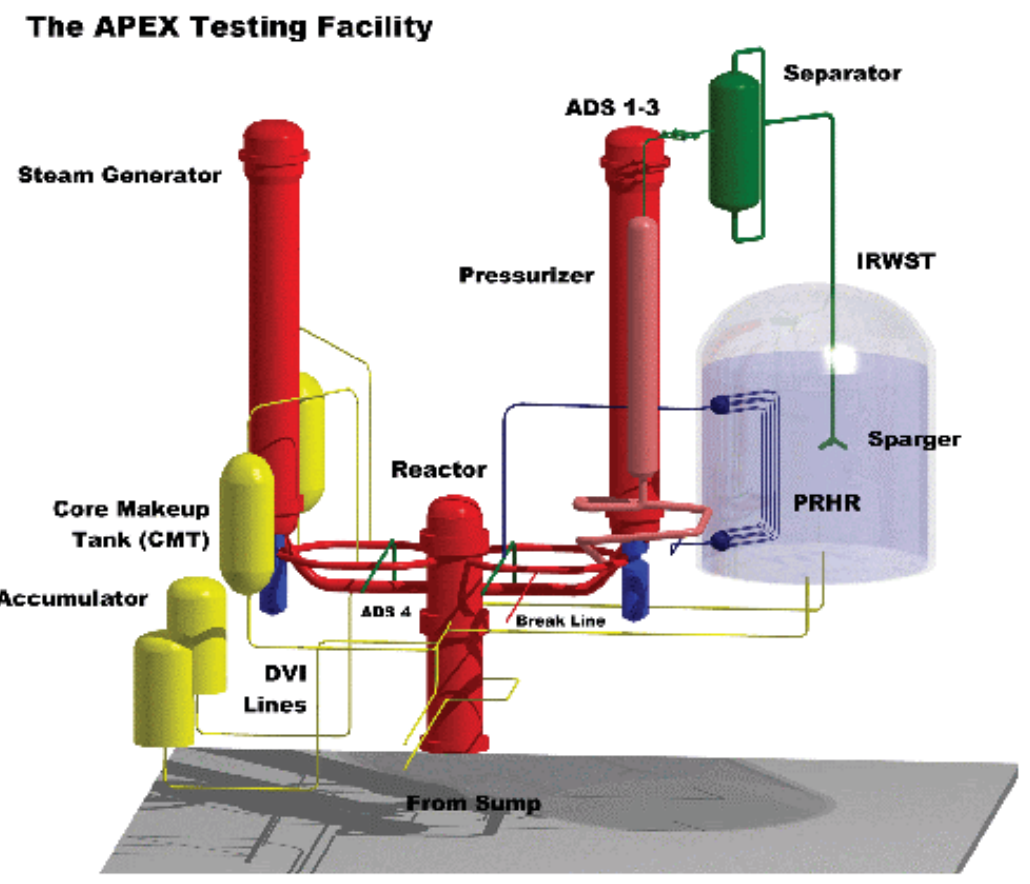

Figure 5: APEX facility at Oregon State University

The APEX test facility at Oregon State University (Figure 5) has been specifically designed and constructed to provide high quality data for use in computer code benchmark calculations for a Westinghouse AP1000 power plant. APEX simulates the reactor coolant system, core makeup tanks, automatic depressurization system, in-containment refueling water storage tank, and the lower containment structures. It is a $1 / 4$ height, $1 / 2$ time scale, reduced pressure and temperature integral systems test facility.

More recently, Germany has constructed the TOPFLOW (Transient TwO Phase FLOW) facility (Figure 6). Licensed for operation in 2003, this thermal hydraulic facility is designed for generic and applied studies of transient two-phase flow phenomena specifically for validating CFD codes, with a partial emphasis on reactor safety. Some of the TOPFLOW specifications include a $4 \mathrm{MW}$ electrical steam generator capable of delivering up to $2 \mathrm{~kg} / \mathrm{s}$ steam at pressures up to $10 \mathrm{MPa}$.



Figure 6: TOPFLOW thermal hydraulic facility in Germany. 


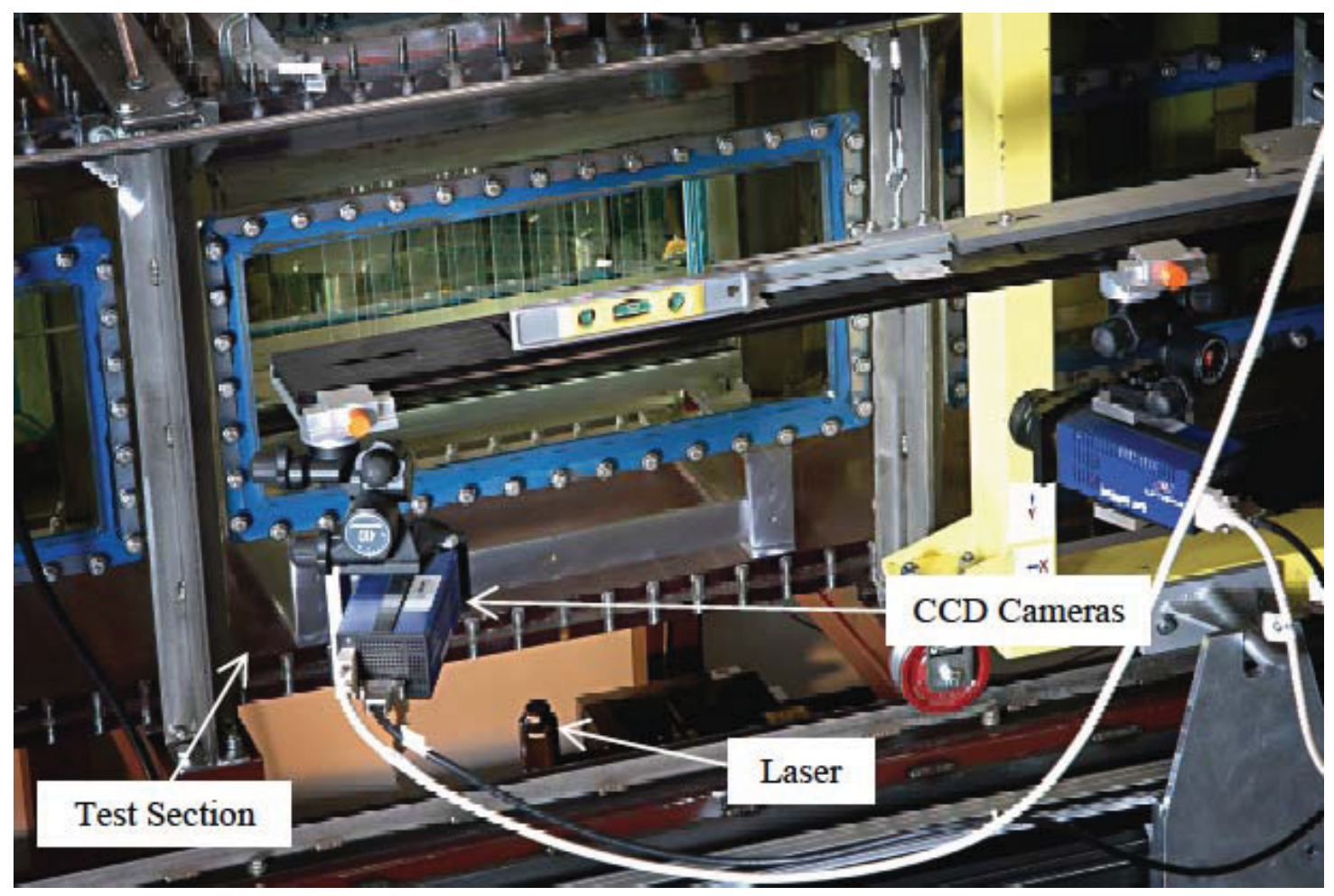

Figure 7: INL MIR test section with PIV system in place.

In 1993, the INL chose to form a new initiative in basic fluid mechanics research and established the Matched Index of Refraction (MIR) flow facility, requiring 5 years of research and development. This general purpose flow facility permits optical-based high resolution velocity measurements (Laser Doppler Anemometry, Particle Image Velocimetry, etc.) within and around objects without locating a disturbing transducer in the flow field and without distortion of the optical paths. The innovative advantage of the INL MIR system is its large size, leading to improved spatial and temporal resolution compared with others. These attributes make the MIR ideal for generating modern experimental data for CFD validation. The system consists of a stainless steel closed flow loop with a polycarbonate and glass test section. The facility operates with light mineral oil as the working fluid (Figure 5). More information concerning the INL MIR can be found in Stoots $(2001)^{8}$. Particle Image Velocimetry has been developed and demonstrated as the main tool within the MIR facility for obtaining validation-quality data on velocity fields for benchmarking and validating CFD turbulence models ${ }^{9}$. The NGNP program has utilized the MIR to study flow fields in the lower plena as a first step towards CFD code validation ${ }^{10}$.

A summary of INL's history in thermal hydraulic experimentation may be found in McCreery et. al., $2007^{11}$. Some of this expertise remains and can be exploited for LWRS program objectives, but some capabilities will need to be developed, modernized, or found elsewhere.

Perhaps the first published formulation of a code validation test matrix was that by Wolfert and Frisch in 1983. ${ }^{12}$ This prompted the formation of an OECD / NEA Committee on Safety on Nuclear Installations (CSNI) sub-group. In 1987, the OECD / NEA PWG2 Task Group on Thermal Hydraulic System Behavior published "CSNI Code Validation Matrix of Thermohydraulic Codes for LWR LOCA and Transients." This document identifies a set of tests that were considered to provide the best basis for the assessment of the performance of thermal hydraulic codes. The set of tests was chosen to include examples of all phenomena expected to occur in plant transients and LOCA analyses. Although the original report biased IETs, a decision was made to develop a distinct SET matrix as well. Nusret Aksan developed several reports ${ }^{13,14}$ which together cross correlate the best available sets of SETs and IETs 
experimental data (as of $\sim 1994$ ) for the assessment, validation, and, finally, the improvement of code predictions of the individual physical phenomena identified. Basically, a simple phenomena identification and ranking table (PIRT) activity was conducted, test types were specified, test facilities suitable for reproducing these aspects were selected, a list of selected experiments carried out in these facilities was created, and a cross correlation matrix was assembled, with weighting values (e.g., suitable, limited suitability, and not suitable).

The U.S. Nuclear Regulatory Commission (NRC) has guidance to organizations intent on licensing (and relicensing) reactor systems. From the perspective of developing and applying thermal-hydraulic and reactivity-specific models to reactor systems, Regulatory Guideline $1.203^{15}$ (RG1.203) gives key guidance to numeric model developers and those tasked with the validation of numeric models. RG1.203 was only released 7 years ago and was derived on the basis of work accomplished to create an analysis tool deemed adequate to analyze the behavior of Generation III+ light water reactors (LWRs) ${ }^{16,17}$. The INL played a lead role in developing this guide by applying it to the validation of AP600 models using data derived from the Oregon State University APEX facility. By creating RG1.203, the NRC defined a framework for assessment and approval of transient and accident analysis methods using numeric tools that are generally known as "systems codes" and "sub-channel codes" 18 which were used extensively in the "90s and are still used today for on-line LWR plants. As a result, this methodology is very relevant for LWRS activities. It is recognized, however, that newly proposed and developed multiphysics and systems analysis tools together with computational fluid dynamics (CFD) codes of all types will also be used for such activities and need to be considered / integrated in any relicensing strategy.

The NGNP Design and Safety Methods Validation program has decided that the practices and procedures for validating software tools for VHTRs should conform to Regulatory Guide 1.203. The NGNP program has identified many of the key phenomena that must be analyzed and continues to advance software tools to address these phenomena. Figure 8 is an example cross correlation matrix developed by the NGNP program. It identifies which SETs or component test facilities are relevant to a sublist of important VHTR postulated accidents, phenomena, or components.

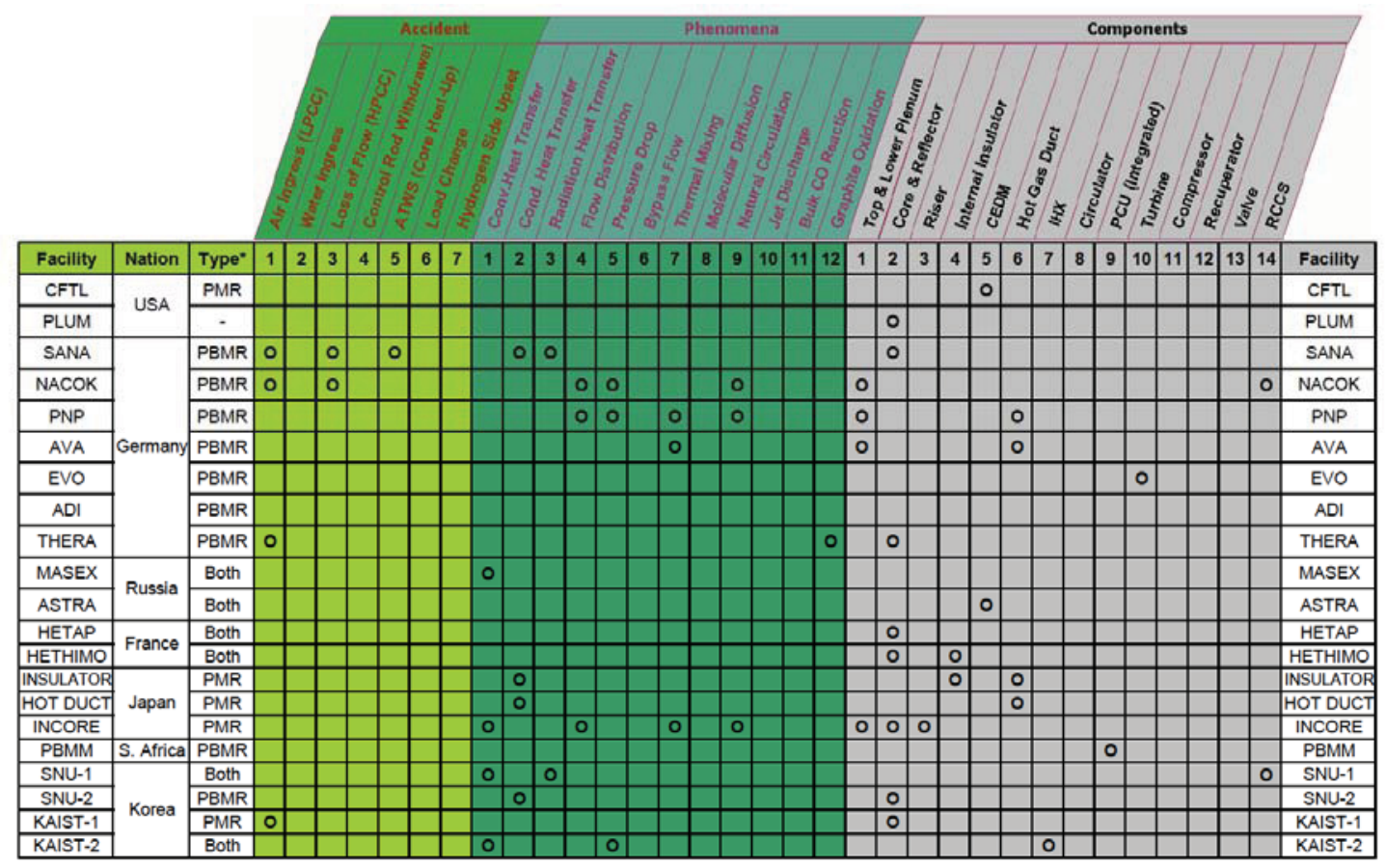

Figure 8: Example cross correlation matrix from the NGNP program. 
Currently, V\&V activities have gained momentum worldwide and span a multitude of industries. The food and drug industry is one of the leaders in software V\&V. The design, production, and distribution of drugs are highly regulated. The Code of Federal Regulations has V\&V requirements for food and drug manufacturing and cleaning processes, as well as the production of medical devices. Health care, economic modeling, accounting practices, and agricultural methodology are just some examples of industries that have embraced and put into practice V\&V.

In the engineering arena, the design and construction of buildings and bridges continue to utilize $\mathrm{V} \& \mathrm{~V}$ to optimize civil engineering computer models. The Department of Defense (DOD) Modeling and Simulation Office is charged with providing consistent modeling and simulation V\&V documentation across the DOD. NASA has long used software V\&V as part of their safety-critical software development efforts. Mission examples include the Deep Space One, X-37, and the $2^{\text {nd }}$ Generation ReUsable Launch Vehicle. ${ }^{19}$ The National Research Council of the National Academies has recently issued two relevant, broadly scoped reports. The first, titled "Evaluation of Quantification of Margins and Uncertainties: Methodology for Assessing and Certifying the Reliability of the Nuclear Stockpile (2008)," ${ }^{20}$ argues that the quantification of margins and uncertainties is a sound and valuable framework that helps the national security laboratories carry out the Department of Energy's responsibility to maintain the nation's nuclear weapons capabilities. The report also suggests that more effort is needed in UQ, including further development of the methodology to identify, aggregate, and propagate uncertainties. Finally, the report advocates that the labs should investigate a "probability of frequency" approach, which separates aleatory and epistemic uncertainties. The second report, titled "Assessing the Reliability of Complex Models: Mathematical and Statistical Foundations of Verification, Validation, and Uncertainty Quantification (2012)"21 provides both a set of principles and best practices for modern V\&V efforts. As an example of one principle in the report:

- Principle: The efficiency and effectiveness of code and solution verification can often be enhanced by exploiting the hierarchical composition of codes and mathematical models, with verification performed first on the lowest-level building blocks and then on successively more complex levels.

- Best practice: Identify hierarchies in computational and mathematical models and exploit them for code and solution verification. It is often worthwhile to design the code with this approach in mind.

- Best practice: Include in the test suite problems that test all levels in the hierarchy.

The list of principles and best practices will be very useful to guide the V\&V strategy for LWRS tools. A survey of existing $V \& V$ databases conducted by the $I N L^{22}$ indicates that the majority of existing $V \& V$ databases are for CFD and exist mainly outside of the nuclear domain. These include the European Research Community on Flow, Turbulence and Combustion (ERCOFTAC) and NASA's NPARC. NPARC is the National Project for Application-Oriented Research in CFD alliance, which is a partnership between the NASA Glenn Research Center and the USAF Arnold Engineering Development Center. Within this alliance, there is a V\&V team responsible for validating the NPARC flow simulations for a wide range of flow parameters and geometric configurations, and to establish an archive of cases that can be accessed by the NPARC community. INL's evaluation of ERCOFTAC and NPARC, as well as other $\mathrm{V} \& \mathrm{~V}$ databases, showed that they are typically repositories for assessment results. The quality and quantity of $\mathrm{V} \& \mathrm{~V}$ data as well as the attendant documentation vary significantly. There are no standards, requirements, or best practices associated with these databases, and no explicit processes of quality assurance.

The Consortium for Advanced Simulation of Light Water Reactors (CASL) is a DOE Energy Innovation Hub for modeling and simulation of nuclear reactors. CASL's vision is to create a virtual reactor for predictive simulations to reduce capital and operating costs, reduce nuclear waste, and enhance nuclear safety. The CASL team has developed their own structured approach to model validation using a set of safety, operating, and design challenge problems. CASL's near-term validation methodology will 
primarily rely upon Tennessee Valley Authority (TVA) plant, PIE measured data (real physical operating reactors) and selected past experimental data to validate the virtual reactor model. Their long-term validation strategy will expand to include identifying and ranking needs, develop recommendations, and support design of experiments to support validation.

The Nuclear Energy Advanced Modeling and Simulation Program (NEAMS) has the objective to rapidly create and deploy "science-based" verified and validated modeling and simulation capabilities essential for the design, implementation, and operation of future nuclear energy systems with the goal of improving U.S. energy security. As part of this effort, NEAMS created a program element called VU focused on verification, validation, and uncertainty quantification. The VU team provided support to the Fuels and Reactors programs in NEAMS for achieving and communicating the credibility required for eventual support of licensing using these advanced simulation tools. As part of this work, the VU team created a set of VVUQ guidelines. ${ }^{23}$ They also focused on assessing the predictive maturity of a simulation code, using a "Discovery, Accumulation, and Assessment process." "24 Finally, they supported some initial work creating a knowledge base called NE-KAMS (Nuclear Energy: Knowledge base for Advanced Modeling and Simulation). The purpose of NE-KAMs is to provide a set of standards, requirements, and best practices associated with data (initially CFD data) used for verification and validation. The NE-KAMS team drafted an initial set of such requirements and standards. ${ }^{25}$ Although the formal VU program element no longer exists in FY13 due to funding limitations, the Reactors and Fuels product lines continue to perform VU tasks.

The INL assisted the US NRC in developing Regulatory Guide 1.203 "Transient and Accident Analysis Methods." This V\&V approach was successfully used for the Westinghouse AP600 design, is still being used today for on-line LWR plants, and is being followed by the INL Next Generation Nuclear Plant (NGNP) project. As a result, this methodology is very relevant for LWRS V\&V activities.

\section{THE STRATEGY FOR VERIFICATION, VALIDATION, AND UNCERTAINTY QUANTIFICATION OF LWRS SIMULATION TOOLS Elements of a VVUQ Strategy}

Significant and continuing advances in computer simulation and rising costs of building and conducting test facilities are increasing the reliance on complex models in licensing facilities, optimizing designs, improving performance, and understanding the underlying science. At the same time, however, the complexity of these models and associated computational methods present unprecedented challenges for code verification, validation, and uncertainty quantification (VVUQ). The challenges are varied and include:

- $\quad$ the need to measure distributed parameter (field) properties with high resolution with minimal disturbance to the field

- the inability to isolate and measure such parameters independently of each other (inadequate or nonexistent measurement techniques and experiments)

- inadequate or nonexistent physical models representing the physics of interest at some scales

- highly nonlinear and stiff numerical models that defy convergence and stability

- immature methods for characterizing and propagating uncertainties in data, modeling, and solution techniques

These and other challenges imply that R\&D is needed in measurement technology, physics, and numerical methods and VVUQ itself. It is not simply a case of applying a standard V\&V practice to an existing code or model; the standard practices themselves must be developed and evaluated simultaneously with the code. The VVUQ task can easily and quickly become diffuse and unmanageable unless there is clear definition of, and strong commitment to, user needs and technical and functional 
requirements of the code. The development team must also be cognizant of the strengths and limitations of the different modeling and simulation methods as well as the maturity of the physical models.

In general, the VVUQ Strategy should:

1. Be driven by the needs of the users (for this program, the LWR industry)

2. Distinguish between and address the needs of licensing, design and performance, and aging/life extension

3. Demonstrate the effectiveness of the methodology by executing one or more well-defined problems early in the process to establish good practices and instill confidence within the user community

4. Utilize a rigorous and integrated approach to code development and VVUQ that is accepted by industry (to inform life-extension decisions) and regulators (if the tools are used to support licensing)

5. Recognize the complementary nature of system and multiphysics/multiscale codes, addressing the unique challenges in VVUQ including gaps in understanding (physical models) and coupling of phenomena across physics, time and length scales

6. Acknowledge and identify gaps in data and re-establish the pedigree of legacy data, exploiting it in a cost-effective manner.

These elements are discussed briefly in the context of the LWRS program, but are applicable to other programs using advanced modeling and simulation.

\section{Driven by Industry}

The LWRS Program works with industry on nuclear energy supply technology R\&D needs of common interest. The interactions with industry are broad and include cooperation, coordination, and direct costsharing activities. These concepts are included in memorandums of understanding, nondisclosure agreements, and cooperative R\&D agreements. Cost-shared activities are planned and executed on a partnership basis and include significant joint management and funding. There is extensive plant operating history from which data can be drawn in addition to the data generated in past research programs sponsored by the federal government. The economic benefits of LWR life extension can also be more easily quantified than those of other DOE advanced reactor development efforts. This represents a valuable opportunity for the development and validation of new simulation codes. The program will only be successful, however, if it remains responsive to, and focused on, user needs. Because these LWRS tools are targeted for use by industry, industry must remain involved in all code development and validation planning, testing, etc. Ultimately, representatives of industry will decide what the codes will do and how well they must perform. Industry involvement includes, but is not limited to:

- Participation in the Phenomenon Identification and Ranking Table (PIRT) process

- Establishment of code technical and functional requirements

- Development of appropriate models

- Specification of acceptance criteria.

\section{Addresses Critical User Needs}

Nuclear system simulation codes have multiple uses each with their own requirements for accuracy and fidelity. For performance or design optimization, a low uncertainty in the value of a key performance parameter may not be as important as its sensitivity to various inputs. Safety analysis calculations for licensing purposes on the other hand may require very well defined and bounded uncertainties upon which operating limits are set. Levels of uncertainty in modeling component or material aging may be particularly large because the physical models may not be well established and the data may be quite limited. Acceptance criteria for simulations will therefore be problem dependent and must be negotiated 
with the user. Similarly, the priority of VVUQ activities (new experiments, code verification testing effort, the requalification of legacy data) must be consistent with the pathways defined with industry input.

\section{Early Demonstration}

VVUQ of an existing code and model for application to a particular problem of interest requires significant resources and time. Validating a new, advanced simulation tool that can simulate a longduration phenomenon such as component aging poses a much greater challenge. It is therefore important to demonstrate early on that the process of VVUQ for this application is on the right track and will yield a tool that the industry will choose to use. The task of validating and verifying the new tool(s) should be planned such that the process can be evaluated and corrected (if needed) at various intermediate stages. Smaller or very well-defined subtasks should be identified for this explicit purpose. For the LWRS program, a near-term application is the simulation of pressurized thermal shock (PTS) of the reactor pressure vessel using Grizzly (a component aging and damage evolution model under development in the LWRS Program). Another near term application is analysis of a BWR station black out as part of a power uprate study. The physical models are well defined and considerable data exist for validating these models.

\section{Rigorous, Integrated Approach}

Regulatory Guideline $1.203^{15}$ (RG1.203) gives key guidance to numeric model developers and those tasked with the validation of numeric models. RG1.203 was released in 2005 and was derived from efforts to create an analysis tool deemed adequate to analyze the thermal-hydraulic behavior of Generation III+ light water reactors By creating RG1.203 the NRC defined a framework within which plant types and perceived transient and accident envelopes, that translates to boundary conditions and thus sets the stage for obtaining the: (a) key phenomena and figures-of-merit which must be analyzed to ensure that the advanced plant can be licensed, (b) specification of the numeric tool capabilities necessary to perform the required analyses - including bounding calculational uncertainties, and (c) specification of the validation matrices and experiments - including the desired validation data.

The protocol outlined in RG1.203 consists of four elements followed by an adequacy decision (see Figure 9). Successful completion of the four elements leads to acceptance of the numeric tool by the user (and regulator if that is the intent). Therefore the rewards for successful completion in a minimum of cycles, ideally only one, are in minimizing costs and time requirements. 


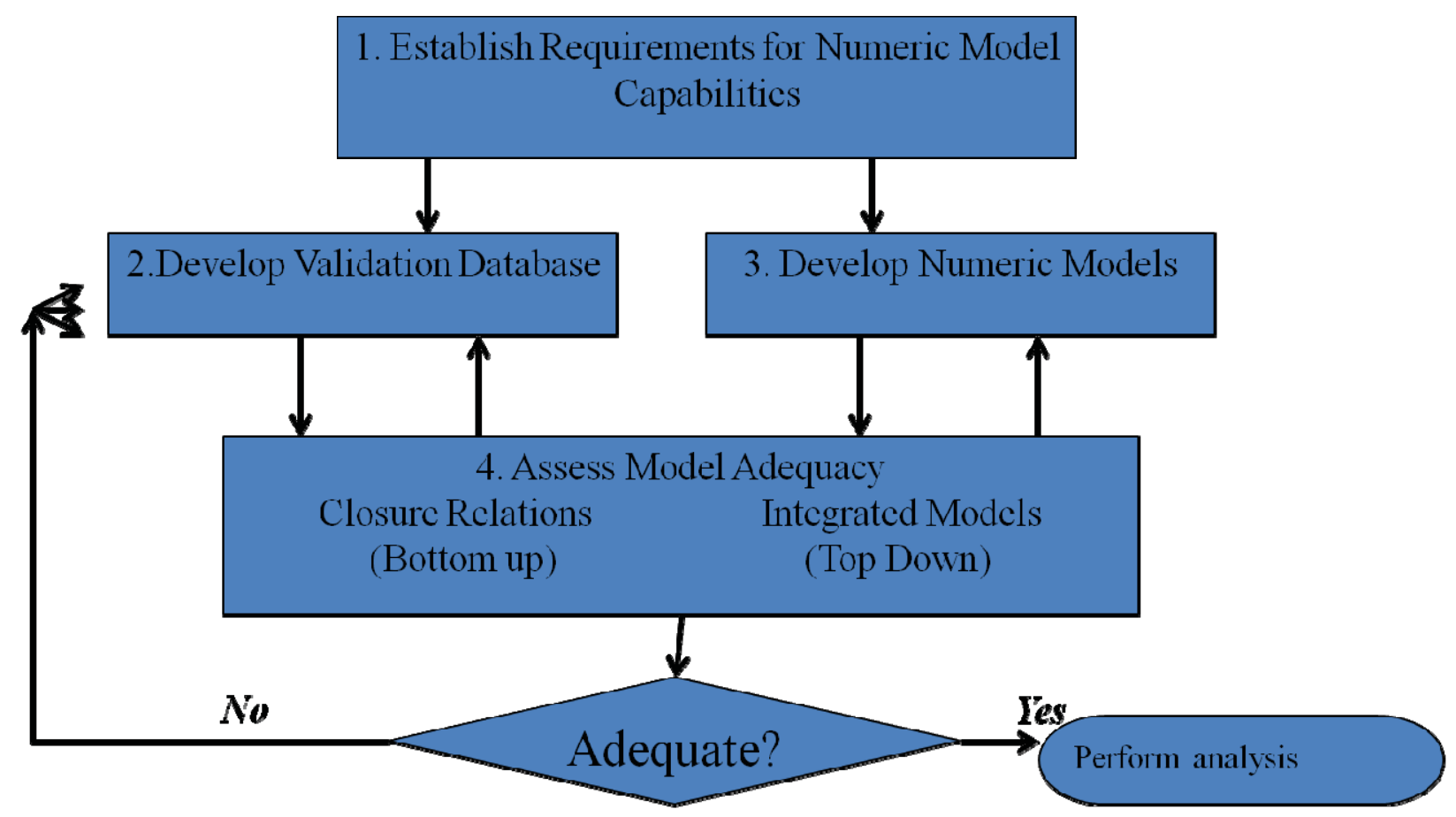

Figure 9: Elements of Code VVUQ under Regulatory Guide 1.203.

Although derived from thermal-hydraulic safety analysis studies and applied to the licensing of the Westinghouse AP600, the technical foundation and approach is equally applicable to a range of fuel, core, and plant simulations for both licensing and performance. It provides the rigor and discipline to address issues of quality and completeness yet it is fully applicable to different codes and models (design, safety analysis, fuel and material performance, multiphysics). It provides an integrated and flexible framework for code and model development and validation. Its application results in a well-defined and limited set of experiments and simulations needed to simulate the behavior of the system within its anticipated operating envelope. The validation and verification practices codified in RG1.203 are being used to develop ASME standards for the application of computational fluid dynamics to nuclear plant simulations. The same approach will be used to validate fuel performance, chemistry, materials aging, and other simulations under LWRS. A detailed discussion of RG1.203 is provided in Appendix A.

\section{V\&V of Both System and Multiphysics Modeling Tools}

The burden associated with validation and verification of modern simulation tools is greater given the additional spatial resolution, extent of the physics being modeled and their interactions, and the multiple length and time scales. Specifically,

a. More separate effects tests at the smaller length/finer physical scales will probably be required than with historical legacy codes to ensure proper closure models are in the code. Note however, that separate effects tests can often provide non-prototypic results as was observed, for example, in German simulated tests of fission product release from LWR fuels under severe accident conditions where they mixed fission products and $\mathrm{UO}_{2}$ and heated the samples up to very high temperatures and measured release.

b. Longer times scales associated with subsequent license renewal can be very difficult to model and validate. Accelerated testing protocols and experiments need to be developed to examine rate effects and determine how to approach both the experimentation and modeling. 
c. Sophisticated, spatially distributed measurements of parameter fields are required to validate high fidelity codes that compute field variables at increasingly fine resolutions in addition to spatially averaged values.

d. Validating the coupling across physics and scales will require a methodical approach to characterizing and prioritizing them so that resources are focused on those that make a difference in key performance and safety parameters.

The additional complexity associated with multiphysics/multiscale simulations requires that a number of issues be addressed during code development.

a. Although most or all of the physical phenomena can be identified and modeled in theory using one coupled simulation, the key performance or safety parameters may not be overly sensitive to many of them and the computational cost of including all of them in the simulation is likely to be prohibitive. A top down approach is therefore needed to guide model development and focus on important phenomena that drive behavior. This entails

i. Sensitivity studies that help to develop a "new intuition" that guides users to model those phenomena. These would come in the form of a hierarchy of test cases (informed by pathway priorities) ranging from simple (single physics) through multiscale/multiphysics simulation. Ideally, these would also be scaled properly and would correspond to the components of the experimental matrix. Low order system models reveal first order sensitivities and thus should be developed or executed in concert with the higher order simulations. This helps to focus detailed modeling where detailed modeling is needed.

ii. Near-term comparison with legacy integral effects test data to ensure that the multiphysics models are capturing relevant phenomena in an integral sense

iii. Establishing how well phenomena at smaller length and relevant time scales need to be known (measurements may not be feasible for some lower-length and extremely long/short time scale behavior); is it acceptable to compare to data at a "higher level" - if data matches model within acceptable error bars, is that enough?

b. Models with complex geometries may pose convergence problems. Test problems should be established to determine the magnitude of the problem

c. There are limitations in multiphase flows (e.g. turbulence, artificial viscosity). Test cases are needed to understand if the limitations are important in the problems at hand

d. Computation hardware may impose a limit on the fidelity of the model. Turbulent flows and transient analysis may require enormous grid sizes or run times. Or, a phenomenon may simultaneously require a large range of length and time scales. Coarse mesh homogenization techniques have been successfully developed and used for neutronics but have yet to be fully explored in other areas. For example, coarse mesh conjugate heat transfer methods that bridge the gap between high fidelity CFD and system models may provide adequate levels of fidelity along with computational efficiency.

e. Grid meshing may introduce errors. Systematic meshing studies are obligatory and should be performed as part of any analysis and should be conducted as part of code verification. Multiphysics code coupling may introduce issues related to time step and spatial resolution. This is being addressed specifically in the current MOOSE development path.

\section{Data Needs}

The development of qualified data to be used in the $\mathrm{V} \& \mathrm{~V}$ process is as important as the code development and validation effort itself. Billions of dollars were spent in the past obtaining data to validate our understanding of reactor systems. While much of the legacy data may not have the requisite pedigree for validation of today's more detailed models, a critical assessment of the pedigree of legacy data needs to 
be a key part of the overall strategy. The data should be scrutinized and its applicability, uncertainty, and quality established early in the $\mathrm{V} \& \mathrm{~V}$ effort. This will then support what new experiments need to be performed. Based on the phenomena that needed to be validated, a matrix of separate, mixed, and integral effects experiments spanning the anticipated length and time scales should be developed in accordance with RG1.203 (Figure 10: Hierarchy of Experiments in a Validation Matrix.). There have been significant advances in measurement technology over the past decades. These advances include measurements at length and time scales (e.g. PIV techniques to provide information about fluid flow, nanotechnologies that allow measurements at the atomistic scale, specialized smart high frequency sensors) that were not possible twenty years ago. In some cases, the measurement techniques are so new that addressing uncertainties is still at the forefront of research. In the area of data qualification, advances in statistical methods and automation can help reduce uncertainties and shorten the data qualification process.

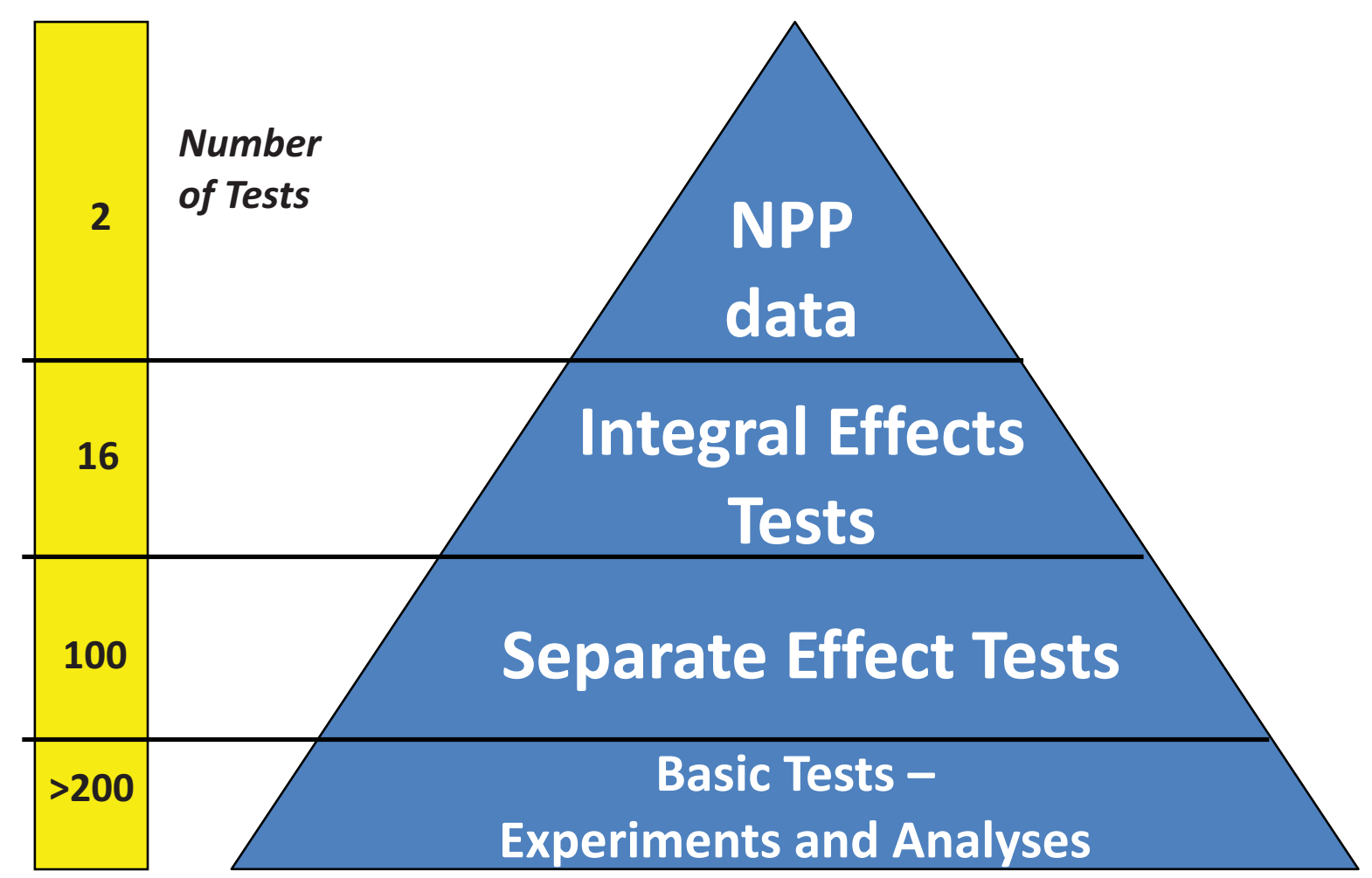

Figure 10: Hierarchy of Experiments in a Validation Matrix. 


\section{APPENDIX A - NRC Regulatory Guide 1.203}

RG1.203 gives key guidance to numeric model developers and those tasked with the validation of numeric models. By creating RG1.203 the NRC defined a framework for development, assessment, and approval of transient and accident analysis methods. This methodology remains very relevant for LWRS code development activities. Per NRC 1.203, there are six basic principles important to follow in model development, V\&V, and acceptance. These six principles are summarized as an Evaluation Model Development and Assessment Protocol (EMDAP). The first four of these are the most important and are termed "elements". These are shown in Figure 11. These are followed by an adequacy decision. The $\mathrm{V} \& \mathrm{~V}$ of a computer code / model occurs in Element 4. Successful completion of the four elements leads to acceptance of the numeric tool and therefore an implied invitation to analyze the plant behavior. It should be noted that a graded approach should be taken to application of the EMDAP. Application of a full EMDAP may not be needed for all assessments. The following four attributes of the EM should be considered when determining the extent to which the full model development process may be reduced for a specific application:

1. novelty of the revised EM compared with the currently acceptable model

2. complexity of the event being analyzed

3. degree of conservatism in the EM

4. extent of any plant design or operational changes that would require reanalysis.

Furthermore, quality assurance protocols and accurate documentation are to be incorporated. When complex computer codes are involved, peer review by independent experts should be an integral part of the quality assurance process. A credible NRC review will require quality assurance and accurate documentation. 


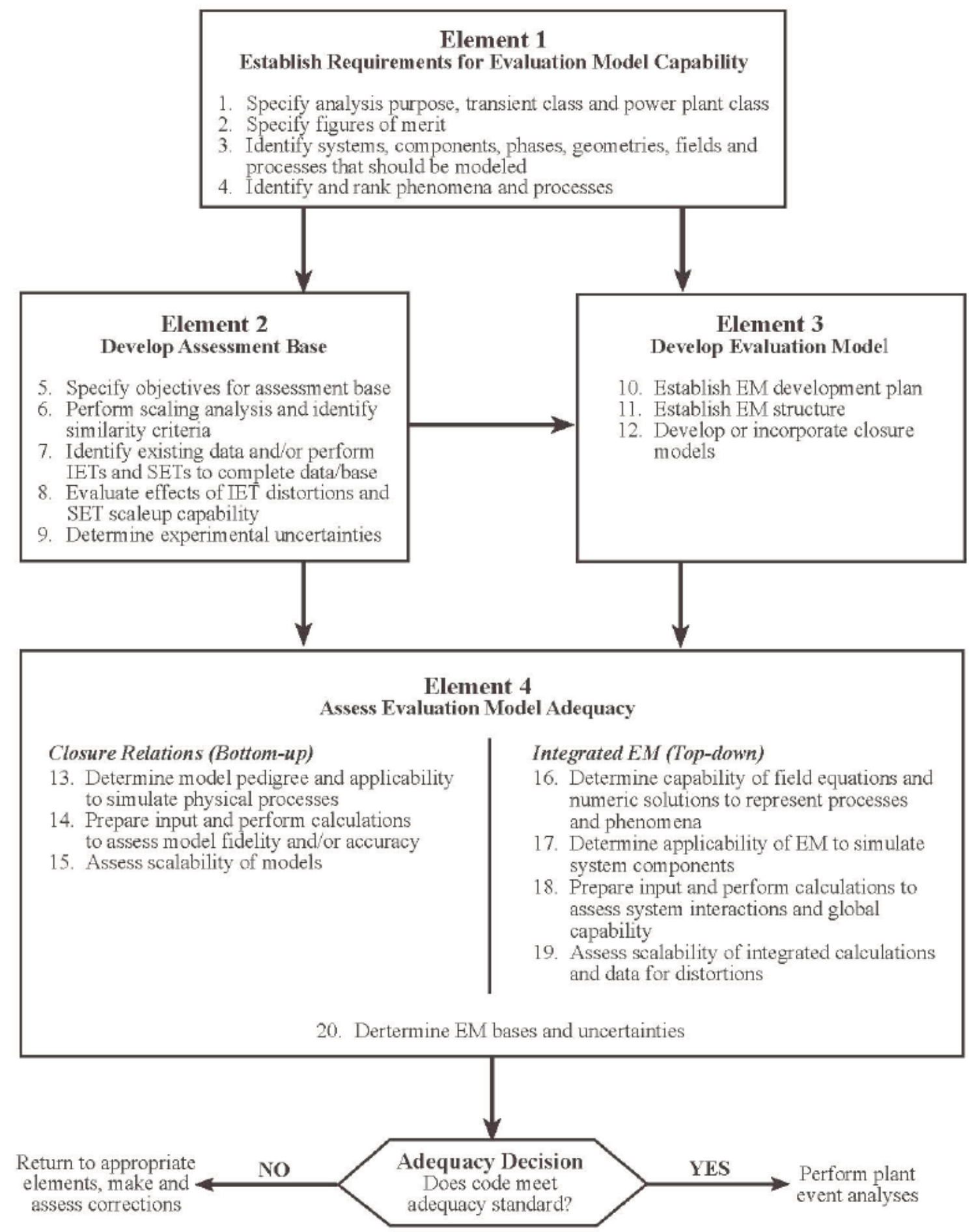

Figure 11: Elements of evaluation model development and assessment process (EMIDAP) ${ }^{12}$. This comprises an integrated structure for technical issue resolution (ISTIR).

\section{Element 1 - Establish Requirements for Evaluation Model Capability}

The boundary conditions for the development and assessment are defined within Element 1. In essence, the plant type, the plant geometry and components and component regions, the desired operating conditions, and the most challenging transient and accident conditions are identified. The desired 
operating conditions, together with most challenging transient and accident conditions are shown abstractly in Figure 12 as the system envelope in Venn diagram form. Given the knowledge of the system envelope and system characteristics, the figures-of-merit used to evaluate the system safety and also the key phenomena for the system envelope are defined usually via creation of the phenomena identification and ranking table (PIRT). Finally, the material properties of the system combined with the anticipated operational, transient, and accident conditions enable the required calculational accuracy to be prescribed in the context of the system licensing requirements.

The PIRT may identify issues that predominate among many existing plants. The PIRT activity should tabulate and consider the traditional and relevant issues that have come up over the history of operations. Issues need to be characterized as safety related (NRC cares), economic, and/or performance. The last two are important to of particular interest to vendors, EPRI, etc. The most challenging phenomena / scenarios must be identified together with a breakdown of the figures-of-merit to enable the experimental / validation matrix to be defined.

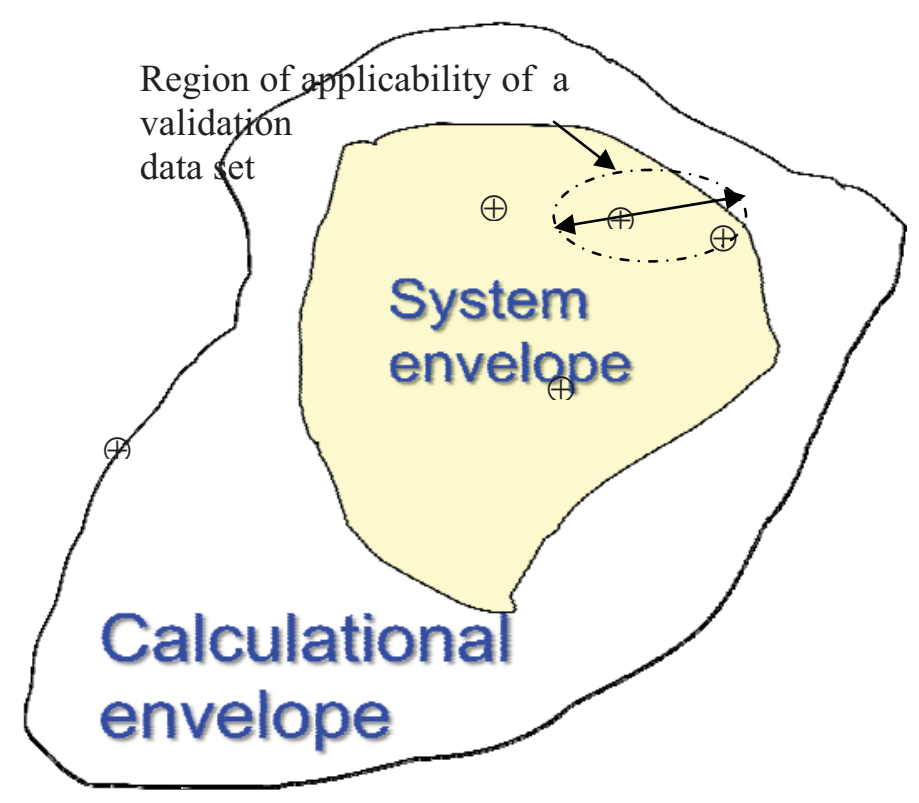

Figure 12: Relationship of validation data to calculation and system envelopes.

\section{Element 2 - Develop Assessment Base}

Using prescribed scaling methodologies and techniques and the system envelope defined in Element 1, the following are defined in this element: calculational domains, data needed for validating the desired numeric tools, and the experiment hardware on the basis of their scaling relationships to the prototype plant such that the key phenomena behavior in the relevant ranges are captured. The experimental atypicalities are also identified ${ }^{26}$. The development of the scaling equations sets and the calculational domain are boundary conditions for prescribing the required numeric models in Element 3.

The experimental data requirement considers nuclear power plant data, scaled integral effects experiments, scaled separate effects experiments, and fundamental data ${ }^{27}$. To assist with development of the validation matrix, a cross correlation matrix should be done with experimental facilities and historical test data. To what extent does relevant experimental data exist, what is its uncertainty, and under what experimental conditions was it derived? Experiments conducted in the past in reactor thermal hydraulics were not required to provide uncertainty estimates. And, for the most part, this was consistent with the 
tools and models used in the past. But as modeling gets into finer resolution models (e.g., CFD), the uncertainty in supporting experimental data needs to be known and tightened.

There are special V\&V considerations if new experiments are required and to be specified. First, it is important to consider scale, since scale affects cost. Also, numbers of measurements and measurement techniques have a direct affect upon cost and may impost distortions of operating conditions ( $T$, $\mathrm{P}$, etc.). Design, construction, and operation of an experiment require time - typically 5 years or more. One challenge will be to find a way to have "fast feedback" in the short term while (re)building gradually an experimental infrastructure to support $\mathrm{V} \& \mathrm{~V}$ in the longer term.

In some cases, there are limited measurement techniques of sufficient spatial / temporal resolution to be useful for $21^{\text {st }}$ century model validation. This is particularly true for two-phase flow CFD analysis. There may have to be some efforts in instrumentation / measurement technique development to support V\&V of modern codes. Furthermore, not all measurement techniques have accepted error quantification methodologies, which limit their applicability to $\mathrm{V} \& \mathrm{~V}$. The INL has taken a lead in experimental error quantification for particle image velocimetry, which is a measurement technique of great pertinence to CFD V\&V. Finally, there are fewer and fewer trained experimentalists. All of these considerations must be factored into the $\mathrm{V} \& \mathrm{~V}$ strategy if new experiments are to be planned.

\section{Element 3 - Develop Evaluation Model}

A cross correlation matrix between PIRT issues and an evaluation model should be developed. This matrix should consider whether for a particular issue a computer model / code is: 1) good to go, 2) marginal, 3) needs work, 4) can compute an issue but the issue is not experimentally measureable, and 5) cannot compute (e.g., concrete degradation). Element 3 defines relevant code options, boundary conditions, and desired degree of calculational uncertainty.

\section{Element 4 - Assess Evaluation Model Adequacy}

This element involves the traditional V\&V analysis. The numeric models and closure relationships are evaluated using a bottom-up and top-down approach to determine their adherence to the desired objectives. The models are verified and benchmarked through comparison to other standards, such as closed-form solutions or results obtained with another code. The numerical solution evaluation should consider convergence, property conservation, and code stability. The models are validated via comparison to relevant experimental data and, where possible, plant operational data. The focus should be upon how well the model can predict the key phenomena of interest or appropriate experimental behavior. Some of this assessment is best made during the early phases of code development to minimize the need for later corrective actions. Since the EM relies to great extent upon models and correlations that are empirical in nature, it is important to ensure that they are used within the range of their assessment. Finally, assess the model uncertainty. Identify differences between calculated and measured data, which may indicate errors, scaling distortions, biases, etc.

Elements 3 and 4 should consider typical modeling limitations. For instance, turbulence modeling remains one of the great remaining engineering challenges and is still a "black art". Multiphase flow modeling still requires much development, and approximations must be used. A similar statement holds true for multicomponent flows. For some situations, fluid thermophysical properties may not be well known (e.g., multicomponent effective viscosity). Complex geometries may hamper code convergence. Multiphysics code coupling may introduce issues related to time step and spatial resolution. Computational hardware may impose limitations - turbulent flows and transient analysis may require enormous grid sizes or run times. Or, a phenomenon may simultaneously require a large range of length and time scales. An example may be the CRUD test model - fine spatial resolution but large time scales. Finally, there are effects of model meshing. Grid generation is often done automatically without engineering insight. 


\section{REFERENCES}

1. U.S. Energy Information Administration, "International Energy Outlook 2007," Energy Information Administration, Office of Integrated Analysis and Forecasting, U.S. Department of Energy Washington, D.C., May 2007.

2. Light Water Reactor Sustainability Program Integrated Program Plan, INL/EXT-11-23452, January, 2012.

3. Independent software verification and validation, Wikipedia.

4. IEEE Standard for Software Verification and Validation Plans, IEEE 1012-1986.

5. IEEE Guide for Software Verification and Validation Plans, IEEE 1059-1993.

6. Guidelines for the Verification and Validation of Scientific and Engineering Computer Programs for the Nuclear Industry, ANSI/ANS-10.4-1987.

7. Nakamura, H., Watanabe, T., Takaeda, T., Maruyama, Y., and Suzuki, M., "Overview of Recent Efforts through ROSA/LSTF Experiments," Nuclear Engineering and Technology, Vol 41, No. 6, August, 2009.

8. Stoots, C. M., et. al., "A large-scale matched index of refraction flow facility for LDA studies around complex geometries," Exp. In Fluids, 30 (2001), pp. 391-398.

9. Dinh, Nam, “CASL Validation Data: An Initial Review,” INL/EXT-11-21017, 2011.

10. McIlroy, H. M. Jr., McEligot, D. M., and Pink, R. J., "Measurement of turbulent flow phenomena for the lower plenum of a prismatic gas-cooled reactor," Nuc. Eng. and Design, 240(2010), pp. 416428.

11. McCreery, G.E., and McIlroy, H.M., "INL Experimental Roadmap for Thermal Hydraulic Code Validation," INL/EXT-07-13248, September, 2007.

12. Wolfert and Frisch, "Proposal for the Formulation of a Validation Matrix", CSNI-SINDOC (83) 117 , 1983.

13. Aksan, N., D’Auria, F., Glaeser, H., Pochard, R., Richards, C., Sjoberg, A., "Separate Effects Test Matrix for Thermal-Hydraulic Code Validation" Volume I: Phenomena Characterisation and Selection of Facilities and Tests and Volume II: Facility and Experimental Characteristics, NEA/CSNI/R (93) 14 / Part 1 and Part 2, Paris 1994.

14. Nusret Aksan "The CSNI Separate Effects Test and Integral Test Facility Matrices for Validation of Best-Estimate Thermal Hydraulic Computer Codes"

15. U.S. Nuclear Regulatory Commission, Regulatory Guideline 1.203, Transient and Accident Analysis Methods, December, 2005.

16. Fletcher, C.D., Bayless, P.D., Davis, C.B., Ortiz, M.G., Sloan, S.M., Shaw, R.A., Schultz, R.R., Slater, C.E., Johnsen, C.E., Adams, J.P., and Ghan, L.S., Adequacy Evaluation of RELAP5/MOD3, Version 3.2.1.2 for Simulating AP600 Small Break Loss-of-Coolant Accidents, INEL-96/0400 (nonproprietary version), April 1997.

17. Schultz, R.R., Kullberg, C.M., McCreery, G.E., Shaw, R.A., Hanson, B., Newman, N., Liou, C.P. and Westcott, J.L., RELAP5/MOD3 Code Assessment Based on the ROSA-AP600 Program: Small Break LOCAs and the Station Blackout Transient, March 1997. 
18. Zuber, N., “Appendix D: A Hierarchical Two-Tiered Scaling Analysis," An Integrated Scaling and Structure Methodology for Severe Accident Technical Issue Resolution, NUREG-CR-5809, November , 1991 (draft report for comment).

19. Pecheur, C., and Nelson, S., "Survey of NASA V\&V Processes/Methods," NASA/CR-2002-211401, April, 2002.

20. National Research Council of the National Academies, "Evaluation of Quantification of Margins and Uncertainties: Methodology for Assessing and Certifying the Reliability of the Nuclear Stockpile." ISBN: 978-0-309-12853-7, The National Academies Press, 2008.

21. National Research Council of the National Academies, "Assessing the Reliability of Complex Models: Mathematical and Statistical Foundations of Verification, Validation, and Uncertainty Quantification.” ISBN: 978-0-309-25634-6, The National Academies Press, 2012.

22. Lee, H., "A Survey of Existing V\&V, UQ and M\&S Data and Knowledge Bases in Support of the Nuclear Energy - Knowledge Base for Advanced Modeling and Simulation (NE-KAMS)," INL/EXT-11-24275, December, 2011.

23. Nelson, R., Unal, C., Stewart, J. and Williams, B. "Using Error and Uncertainty Quantification to Verify and Validate Modeling and Simulation." LA-UR-10-06125.

24. Knupp, P. and A. Urbina. “A Design for a V\&V/UQ Discovery Process" SAND 2011-6677.

25. Weirs, V.G., Mousseau, K.C., Johnson, R.W., Lee, H., Oberkamps, W.L., Smith, B., Fort, J., and Rider, W.J. "NE-KAMS Code Verification and Validation Data Standards and Requirements: Fluid Dynamics, Version 1.0.” FCRD-NEAMS-2011-000393.

26. Reyes, J. N., and Hochreiter, L., "Scaling Analysis for the OSU AP600 Simulator (APEX)," Nuclear Engineering and Design Journal, 186, 1998, pp 58-109.

27. Levy, S., Two-Phase Flow in Complex Systems, J. Wiley, 1999. 